\title{
Las normales rurales como semillero de conciencia social
}

\section{Teacher's college as a seed of social conscience}

\author{
María de los Ángeles González Vega ${ }^{1}$
}

\begin{abstract}
Resumen
En los últimos años las Escuelas Normales Rurales se han situado como materia de debate educativo. Sus características particulares y su historia han generado distintos puntos de vista -algunos contradictorios- sobre la pertinencia de su continuidad. No obstante, la gran mayoría de las opiniones se sustentan en prejuicios o bien en perspectivas sesgadas. El presente documento reflexivo pretende coadyuvar en la construcción de una visión general, revelando la trascendencia de las Escuelas Normales Rurales mexicanas -y de sus egresados- en la transformación de prácticas pedagógicas y procesos sociales.
\end{abstract}

\section{Palabras clave}

Normales rurales, organización estudiantil, lucha social, FECSM, movilizaciones.

\begin{abstract}
In recent years, the Normales Rurales Schools have been placed as a matter of educational debate. Its particular characteristics and history have generated different points of view, some contradictory, on the continuity relevance. However, the vast majority of opinions are based on prejudices or biased perspectives. This reflexive document intends to contribute to the construction of a general vision, revealing the importance of the Mexican Rural Normal Schools - and their graduates - in the transformation of pedagogical practices and social processes.
\end{abstract}

\footnotetext{
1 María de los Ángeles González Vega. Maestra frente a grupo dependiente de la Secretaría de Educación y Deporte, Chihuahua, México. Licenciada en educacion primaria por la Escuela Normal Rural Ricardo Flores Magón y Maestra en Pedagogía Crítica por el Instituto de Pedagogía Crítica (IPEC). Correo electrónico: gely320@hotmail.com

ID: https://orcid.org/0000-0001-7310-030X
} 
RECIE. Revista Electrónica Científica de Investigación Educativa Vol. 4, núm. 2, enero-diciembre 2019, pp. 1381-1387.

\section{Keywords}

Normales Rurales, student organization, social fights, FECSM, mobilizations.

\section{Introducción}

Las Escuelas Normales Rurales se distinguen de otras instituciones educativas del país principalmente por la participación activa de sus alumnos en movilizaciones y protestas encaminadas a mejorar sus condiciones de estudio, o simplemente por solidaridad con otras luchas sociales.

Giroux (1985) indica que la educación pública ofrece muchas posibilidades, ya que en la escuela conviven estudiantes de diversos contextos sociales que interactúan de diversas maneras. Si bien estas experiencias actualmente son cada vez más escasas, en los internados tienen un elemento afectivo y formativo muy especial, generado por la convivencia en el mimo espacio durante tiempo prolongado. Este factor explica el compromiso social que demuestran buena parte de sus egresados, el cual explicaré a continuación.

Organización estudiantil que aglutina a las normales rurales y que fomenta el intercambio, la cooperación y la solidaridad entre normalistas

Las situaciones de origen social y la formación políticas que experimentan los y las estudiantes antes y durante su estancia en la escuela normal, son la base para la movilización de una forma de conciencia de clase denominada "solidaridad" (García, 2015).

La Federación de Estudiantes Campesinos Socialistas de México (FECSE) aglutina a todas las normales rurales del país. Se organiza clandestinamente para elegir a sus representantes nacionales, quienes se encargan de velar por los intereses de todas las instituciones agrupadas y para salvaguardar los estatutos que han conservado por varias décadas. Cuando alguna normal rural enfrenta problemáticas con las autoridades de su estado, la FECSM hace un llamado para apoyarla, dando peso político que impacta en los medios de comunicación.

La matrícula escolar de estas escuelas está conformada por jóvenes de origen humilde y algunos de ellos han pertenecido a organizaciones campesinas que los forman con ideales libertarios de corte marxista. Cuando ingresan a una normal rural, aportan sus experiencias para la formación de una cultura institucional que renueva las bases ideológicas del centro. 
En las normales rurales se viven grandes experiencias de lucha estudiantil. El autogobierno de los alumnos se encarga de la toma de decisiones a través de las asambleas ordinarias, donde se informa y organiza la protección de la escuela. Existe un marcado interés por participar en la toma de decisiones a través de diversos comités que hacen efectiva una verdadera democracia estudiantil. En cada órgano se analizan cuestiones de desarrollo académico, cultural, productivo, deportivo y político marcadas en los estatutos. Estos aspectos forman la ideología propia de estas instituciones.

En las normales rurales las pláticas y discusiones son cotidianas. El ejercicio asambleario, la democracia de mayoría absoluta y la presentación de argumentos son característicos. García (2015) menciona que durante un día cotidiano hay debates que abarcan lo académico; el transporte para ir a una práctica o una presentación cultural o deportiva; el presupuesto de la ración, etc. Cada grupo tiene representantes de carteras que son los que avalan las propuestas de manera democrática, exponiendo argumentos y contraargumentos para la organización de cada actividad.

En las asambleas se llega a acuerdos democráticos propuestos por los alumnos. Las decisiones que se toman son respetadas por todos o -si es necesario- se modifican las propuestas del comité. Cada propuesta se somete a votación, argumentando cada quien su posicionamiento. En las asambleas ordinarias todos los grupos de primero a cuarto grado tienen derecho a participar y votar.

Algunos estudiantes normalistas han llevado sus estrategias de acción y movilización política hacia la creación de nuevas organizaciones y en favor de las demandas de su gremio (García, 2015).

Los alumnos se identifican con las teorías marxistas-leninistas que se revisan al interior del Comité de Orientación Política e Ideológica(COPI). En este espacio se recibe la preparación ideológica y se fomenta la disciplina y coherencia del discurso de los estudiantes.

El COPI es una cartera de peso en la estructura organizativa de las normales rurales. Allí se analiza la sociedad y los acontecimientos que ocurren en el ámbito mundial, nacional y municipal, predominando el punto de vista crítico, debido a que estos fenómenos de alguna forma impactan en el normalismo rural. Los temas son preparados por los mismos alumnos que revisan aspectos filosóficos, estudios de las revoluciones o de movimientos históricos que han dejado huella dialéctica en la humanidad. La sobrevivencia de las normales rurales se debe mucho a esta cartera de formación ideológica.

La larga tradición de lucha de las normales rurales procede de la herencia cardenista y la influencia de la FECSM constituye una de las pocas 
organizaciones independientes donde se manifiesta la fuerza del movimiento estudiantil (Téllez, 2005).

Téllez (2005) reconoce que el mayor auge de estas instituciones fue durante el sexenio del presidente Lázaro Cárdenas, cuando fue oficializada la educación socialista. El mismo presidente de la República depositó la confianza en estos espacios educativos y en sus estudiantes para impulsar su proyecto de cambio social. La sólida formación ideológica ha permitido que las escuelas normales persistan a pesar de las adversidades que enfrentan hoy en día.

Los alumnos imprimen una dinámica especial a estos espacios educativos de formación docente, ya que son ellos la fuerza del movimiento. Sus convicciones hacia la institución y su disciplina permiten la conservación de su organización de origen, al igual que la que persiste en la FECSM. La permanencia de sus estatutos ayuda en la transmisión de una herencia formada durante varias generaciones.

Organización estudiantil interna con autonomía de la administración escolar La ideología de los internados nació en un ambiente social donde prevalecían los ideales liberales y revolucionarios. Las organizaciones estudiantiles fueron formadas para la defensa de los internados (Aguayo, 2002).

La ideología revolucionaria, que se ve fortalecida en la dinámica cotidiana de los internados, y la interacción ideológica de todos los alumnos se lleva a la práctica por medio del debate y la disciplina. Esto evita que se caiga en contradicciones al momento de actuar.

Desde la fundación de estas escuelas es posible advertir el amor que los estudiantes tienen hacia su internado, dado que es el que permite desarrollar su ideología. En él se adquiere la formación política y la conciencia para tomar acuerdos y decisiones dentro de las asambleas.

Las escuelas son instituciones relativamente autónomas que no solo proporcionan espacios para comportamientos de oposición y para la enseñanza. Las escuelas no se rigen solo por la lógica del lugar de trabajo o de la sociedad dominante, sino que también son ámbitos políticos, culturales e ideológicos (Giroux, 1985).

Las normales rurales tienen su propia esencia y manejan su autonomía, manteniendo su organización alejada de las decisiones de los directivos de la escuela. Esta característica ayuda a que el comité estudiantil se encargue de velar por el bienestar de la base de manera libre. 
Formación ideológica informal orientada al bienestar de los sectores más desfavorecidos de la sociedad

Los normalistas rurales adoptaron el género de la "huelga" para demostrar sus inconformidades y hacer valer su derecho a becas dignas, mejores instalaciones, incidir en la conducta de los maestros y para ser tomados en cuenta en la designación de los directivos del plantel (García, 2015).

En estas escuelas, los alumnos son los que le dan la verdadera esencia. Gestionan el bienestar del plantel por medio del pliego petitorio anual que se construye con el debate entre alumnos y autoridades educativas. En ese documento se reafirma la petición de respeto a la organización estudiantil y la demanda de mejores condiciones en el internado.

García (2015) rescata algo muy importante en relación a la forma en que los mismos alumnos demuestran la autonomía en su forma de organizarse y de actuar. Si un profesor no cumple con los requisitos en su forma de enseñanza, el alumnado presenta la queja para que sea cambiado a otro espacio educativo, ya que en ocasiones algunos de ellos sólo perjudican a la institución y no cumplen profesionalmente con su función.

\section{Una larga tradición de activismo político}

Las escuelas proporcionan a las diferentes clases y grupos sociales el conocimiento y las habilidades para ocupar un lugar respectivo en una fuerza de trabajo estratificada en clases, razas y sexos. Las escuelas son reproductoras en el sentido cultural (Giroux, 1985).

Guiroux (1985) describe que las escuelas están integradas por incomparables grupos sociales, donde cada alumno pertenece a un contexto diferente de la sociedad. Las escuelas logran una gran posición cultural al momento de agrupar a todos los alumnos con diferentes estatus, creando así nuevas perspectivas en las comunidades estudiantiles.

En las escuelas normales se inculca la ideología del internado desde que llegan los alumnos de nuevo ingreso -o la "nueva sangre", como se les llama-; tratando de concientizarlos mediante la presentación de la realidad que se vive dentro del país y de la situación particular de la escuela normal rural a la cual pertenecen.

El COPI es el organismo encargado de dar clases de orientación política mediante círculos de estudio. En ellos se revisan temas como: reformas, esencia del normalismo rural y movilizaciones sociales ocurridas a lo largo de la historia de la humanidad. Son los mismos alumnos quienes enseñan a los nuevos elementos los aspectos de política, lo que representa una forma de educación paralela a la que se incluye en el currículo oficial. 
El Estado no es meramente una expresión de lucha de clases, es -ante todouna organización que defiende activamente a la sociedad capitalista, mediante medios represivos o ideológicos. El Estado limita y canaliza las respuestas que las escuelas puedan dar a la ideología, cultura y hacia las prácticas que caracterizan a la sociedad dominante (Giroux, 1985).

Las normales rurales, desde su creación, han encabezado grandes movimientos estudiantiles que marcaron la vida de la comunidad estudiantil. Las huelgas han fomentado una forma de lucha y conciencia social. Esto cobra sentido con la cita de Engels (2015) cuando dice que: "Sólo la manifestación de las relaciones de una lucha de clases que ya se está desarrollando, de un movimiento histórico que está sucediendo frente a nosotros" (p. 38).

Como se ha dicho en este documento, los estudiantes de las normales rurales se han dado a conocer por sus formas de lucha, donde su ideología está basada en el marxismo-leninismo. Sus movilizaciones históricas han dejado huella en la educación de México -particularmente normalista-, jugando un papel importante dentro del Estado y de la sociedad en general.

La lucha estudiantil de estas escuelas sigue vigente en la práctica educativa de sus egresados. La conciencia social se forma en sus experiencias como alumnos y se sigue desarrollando durante toda la vida. Las luchas estudiantiles han traspasado varias décadas y aún siguen vigentes.

Al egresar de las normales rurales, una gran cantidad de nuevos docentes llevan consigo la consigna de liberar al pueblo oprimido, creando conciencia por la liberación de la explotación. El perfil de egreso a que se aspira incluye la esperanza de regresar la imagen de aquel viejo profesor luchador social que velaba por los intereses del pueblo oprimido.

\section{Conclusión}

Las Escuelas Normales Rurales son centros educativos de educación superior con particularidades propias que las hacen objeto de bastos estudios desde múltiples perspectivas. Son instituciones que forjan a un estudiantado crítico, involucrando activamente en la transformación de su contexto. Es sustancial tomar en cuenta que para comprender lo heterogéneo del sistema educativo nacional es necesario el analizar el normalismo rural desde un enfoque multidisciplinar. Así es como en el presente trabajo se aspiró a revisar uno de los múltiples campos temáticos: la formación de la conciencia social en la práctica pedagógica y la vida estudiantil. 


\section{Referencias}

Aguayo, J. L. (2002). Escuela Normal Rural de Salaices formadora de maestros. México: José Luis Aguayo.

Engels, K. M. (2015). Manifiesto Comunista. México, DF: Grupo editorial Tomo.

García, A. (2015). La revolución que llegaría. México, DF: Enrique Montes Hernández .

Giroux, H. (1985). Teorías de la reproducción y la resistencia en la nueva sociología de la educación: un análisis crítico. México. D.F: Editorial ERA.

Téllez, A. (2005). Un panorama histórico del normalismo rural. El caso de "El Mexe": el conflicto estudiantil y politpico de 2003-2005. México: Universidad Autónoma Metropolitana. 
RECIE. Revista Electrónica Científica de Investigación Educativa Vol. 4, núm. 2, enero-diciembre 2019, pp. 1381-1387. 